\title{
Investigation of water adsorption and hygroscopicity of atmospherically relevant particles using a commercial vapor sorption analyzer
}

\author{
Wenjun Gu ${ }^{1,4}$, Yongjie $\mathbf{L i}^{2}$, Jianxi Zhu ${ }^{3}$, Xiaohong Jia $^{1,4}$, Qinhao Lin ${ }^{1}$, Guohua Zhang ${ }^{1}$, Xiang Ding ${ }^{1}$, Wei Song ${ }^{1}$, \\ Xinhui Bi ${ }^{1}$, Xinming Wang ${ }^{1,5}$, and Mingjin Tang ${ }^{1}$ \\ ${ }^{1}$ State Key Laboratory of Organic Geochemistry and Guangdong Key Laboratory of Environmental Protection and Resources \\ Utilization, Guangzhou Institute of Geochemistry, Chinese Academy of Sciences, Guangzhou 510640, China \\ ${ }^{2}$ Department of Civil and Environmental Engineering, Faculty of Science and Technology, University of Macau, Avenida da \\ Universidade, Taipa, Macau, China \\ ${ }^{3}$ CAS Key Laboratory of Mineralogy and Metallogeny and Guangdong Provincial Key Laboratory of Mineral Physics and \\ Material Research and Development, Guangzhou Institute of Geochemistry, Chinese Academy of Sciences, Guangzhou \\ 510640, China \\ ${ }^{4}$ University of Chinese Academy of Sciences, Beijing 100049, China \\ ${ }^{5}$ Center for Excellence in Regional Atmospheric Environment, Institute of Urban Environment, Chinese Academy of \\ Sciences, Xiamen 361021, China \\ Correspondence to: Mingjin Tang (mingjintang@gig.ac.cn)
}

Received: 6 March 2017 - Discussion started: 6 April 2017

Revised: 7 September 2017 - Accepted: 19 September 2017 - Published: 18 October 2017

\begin{abstract}
Water adsorption and hygroscopicity are among the most important physicochemical properties of aerosol particles, largely determining their impacts on atmospheric chemistry, radiative forcing, and climate. Measurements of water adsorption and hygroscopicity of nonspherical particles under subsaturated conditions are nontrivial because many widely used techniques require the assumption of particle sphericity. In this work we describe a method to directly quantify water adsorption and mass hygroscopic growth of atmospheric particles for temperature in the range of 5$30^{\circ} \mathrm{C}$, using a commercial vapor sorption analyzer. A detailed description of instrumental configuration and experimental procedures, including relative humidity $(\mathrm{RH})$ calibration, is provided first. It is then demonstrated that for $\left(\mathrm{NH}_{4}\right)_{2} \mathrm{SO}_{4}$ and $\mathrm{NaCl}$, deliquescence relative humidities and mass hygroscopic growth factors measured using this method show good agreements with experimental and/or theoretical data from literature. To illustrate its ability to measure water uptake by particles with low hygroscopicity, we used this instrument to investigate water adsorption by $\mathrm{CaSO}_{4} \cdot 2 \mathrm{H}_{2} \mathrm{O}$ as a function of $\mathrm{RH}$ at $25^{\circ} \mathrm{C}$. The mass hygroscopic growth factor of $\mathrm{CaSO}_{4} \cdot 2 \mathrm{H}_{2} \mathrm{O}$ at $95 \% \mathrm{RH}$, relative to that under
\end{abstract}

dry conditions $(\mathrm{RH}<1 \%)$, was determined to be $(0.450 \pm$ $0.004) \%(1 \sigma)$. In addition, it is shown that this instrument can reliably measure a relative mass change of $0.025 \%$. Overall, we have demonstrated that this commercial instrument provides a simple, sensitive, and robust method to investigate water adsorption and hygroscopicity of atmospheric particles.

\section{Introduction}

Atmospheric aerosol particles, directly emitted by natural and anthropogenic processes or secondarily formed in the atmosphere, have significant impacts on air quality, visibility, human health, and radiative and energy balance of the Earth system (Pöschl, 2005; Seinfeld and Pandis, 2006). The ability to uptake water is among the most important physicochemical properties of aerosol particles, and it largely determines their impacts on atmospheric chemistry and climate (Martin, 2000; Rubasinghege and Grassian, 2013; Farmer et al., 2015; Tang et al., 2016). The ability of aerosol par- 
ticles to uptake water depends on particle composition, relative humidity (RH), and temperature (Martin, 2000; Tang et al., 2016). Under subsaturated conditions (RH $<100 \%)$, the ability to uptake water is typically called water adsorption in surface science and hygroscopicity in aerosol science (Tang et al., 2016). Under supersaturated conditions, aerosol particles can be activated to cloud droplets (McFiggans et al., 2006; Petters and Kreidenweis, 2007) and ice particles if temperature is below $0{ }^{\circ} \mathrm{C}$ (Pruppacher and Klett, 1994; Vali et al., 2015).

Hygroscopicity of atmospheric particles has been extensively investigated by a large number of studies, and many experimental techniques have been developed. These techniques have been summarized and discussed by a very recent review paper (Tang et al., 2016), and here we only mention widely used ones. For airborne monodisperse particles typically produced by a differential mobility analyzer (DMA), the hygroscopicity can be determined by measuring their diameters at dry (typically at $\mathrm{RH}<15 \%$ or lower) and humidified conditions (Swietlicki et al., 2008; Freedman et al., 2009; Robinson et al., 2013; Lei et al., 2014). Typically, the diameter change is determined by using a scanning particle mobility sizer (in which mobility diameters are measured) (Vlasenko et al., 2005; Swietlicki et al., 2008; Herich et al., 2009; Koehler et al., 2009; Wu et al., 2011) or aerosol extinction cavity ring-down spectrometry (in which optical diameters are measured) (Freedman et al., 2009; Attwood and Greenslade, 2011). These techniques require an underlying assumption that particles are spherical. However, a few important types of particles in the troposphere, including mineral dust and soot, are known to be nonspherical (Veghte and Freedman, 2012; Ardon-Dryer et al., 2015). Therefore, although these techniques can provide useful information, it is difficult to quantitatively determine the amounts of water associated with nonspherical particles at a given RH (Tang et al., 2016). Single particle levitation techniques, which measure light scattering intensity to determine the size (and thus the hygroscopic growth) of levitated particles, also have similar drawbacks (Krieger et al., 2012).

There are several techniques which can be applied to quantify the amount of water associated with nonspherical particles at given temperature and RH. For example, adsorbed water can be measured by Fourier-transform infrared spectroscopy by its infrared absorption at around 3400 and $1645 \mathrm{~cm}^{-1}$ (Goodman et al., 2001; Frinak et al., 2005; Ma et al., 2010a). However, it is nontrivial to convert infrared absorption intensity to the amount of adsorbed water (Schuttlefield et al., 2007a; Tang et al., 2016). Several previous studies have used quartz crystal microbalance (QCM) to measure deliquescence relative humidity (DRH) and mass hygroscopic growth of particles (Schuttlefield et al., 2007b; Arenas et al., 2012; Liu et al., 2016; Yeşilbaş and Boily, 2016). The frequency change of the quartz crystal in a QCM, according to the Sauerbrey equation, is proportional to the change in mass of particles loaded on the crystal (Schuttlefield et al., 2007b). In addition, the amount of water associated with particles at a given $\mathrm{RH}$ can also be determined by measuring the change in water vapor pressure before and after exposure of particles to water vapor (Ma et al., 2010b, 2012), in a manner similar to the determination of Brunauer-Emmett-Teller surface area. In theory the electrodynamic balance can be used to investigate the mass hygroscopic growth of nonspherical particles (Chan et al., 2008; Lee et al., 2008; Pope, 2010; Griffiths et al., 2012). To our knowledge, however, this technique has not been applied to mineral dust and soot particles yet.

In this work we have developed an experimental method to investigate water adsorption and hygroscopicity of atmospheric particles, using a vapor sorption analyzer which is commercially available. We note that two groups have used similar techniques to measure water adsorption by $\mathrm{CaCO}_{3}$ and Arizona test dust (Gustafsson et al., 2005) and DRH of malonic acid, sodium oxalate, and sodium malonate (Beyer et al., 2014; Schroeder and Beyer, 2016). Nevertheless, the performance of this technique has never been systematically evaluated. To validate this experimental method, we have determined DRHs of six compounds as a function of temperature from 5 to $30^{\circ} \mathrm{C}$, and the measured DRHs, varying from $\sim 20$ to $\sim 90 \% \mathrm{RH}$, show excellent agreement with literature values. In addition, mass hygroscopic growth factors (MGFs) of $\left(\mathrm{NH}_{4}\right)_{2} \mathrm{SO}_{4}$ and $\mathrm{NaCl}$ have been measured as a function of $\mathrm{RH}$ at 25 and $5{ }^{\circ} \mathrm{C}$, and the measured MGFs agree very well with those predicted by the E-AIM model (http:// www.aim.env.uea.ac.uk/aim/aim.php; last accessed: 11 January 2017). Detailed descriptions of the E-AIM model can be found elsewhere (Clegg et al., 1998; Friese and Ebel, 2010). Hygroscopic growth factors, calculated using the EAIM model, have been widely used to compare with experimental measurements to verify the performance of a variety of instruments, techniques, and/or methods developed for hygroscopic growth studies (Pope et al., 2010; Lei et al., 2014; Estillore et al., 2016). We show that this instrument can measure a relative mass change (due to water uptake) of $<0.025 \%$ within $6 \mathrm{~h}$ and $<0.05 \%$ within $24 \mathrm{~h}$, and the accuracy of mass change measurement is mainly limited by baseline drifts. These features make this instrument particularly useful for laboratory studies of water adsorption by nonspherical particles and/or particles with low hygroscopicity.

\section{Experimental section}

The instrument used in this work is a vapor sorption analyzer (Q5000SA) manufactured by TA Instruments (New Castle, DE, USA). The first part of this section provides a general description of this instrument, and the second part describes experimental methods used in this work. 


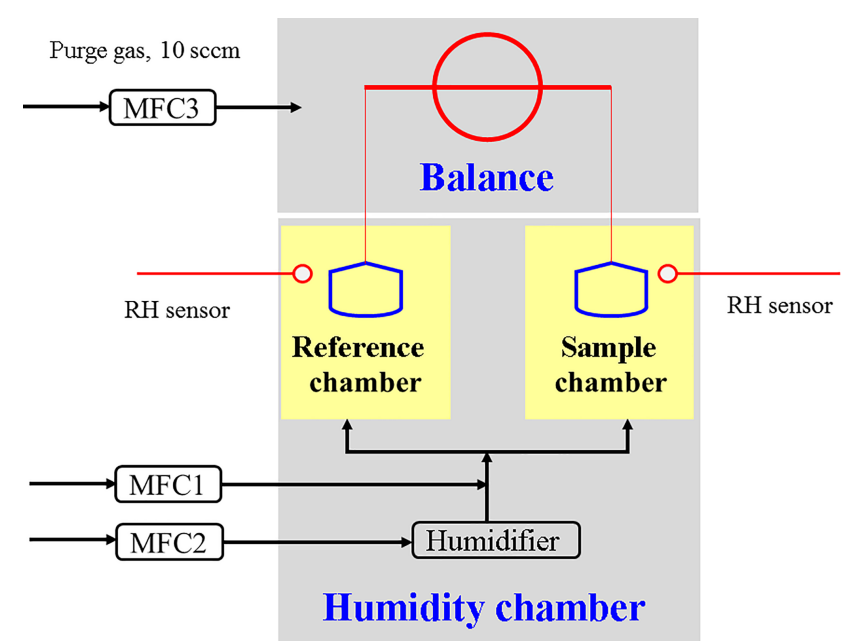

Figure 1. Schematic diagram of Q5000SA used in this work. MFC: mass flow controller. High-purity $\mathrm{N}_{2}$ is used for all the three gas flows regulated by MFC1, MFC2, and MFC3, respectively.

\subsection{Instrument description}

Figure 1 shows the schematic diagram of the vapor sorption analyzer used in this work to measure hygroscopicity and water adsorption of particles of atmospheric relevance. This instrument consists of two main parts: (1) a high-precision balance used to measure the mass of samples and (2) a humidity chamber in which temperature and RH can be precisely regulated and also monitored online.

\subsubsection{High-precision balance}

The balance simultaneously measures the mass of an empty pan (serving as a reference) and a sample pan which contains particles under investigation. Each pan is connected to the balance by a hang-down wire which has a hook at the lower end to hold the pan. The balance is housed in a chamber which is temperature regulated. To avoid moisture condensation, the balance chamber is purged with a $10 \mathrm{sccm}$ (standard cubic centimeter per minute) $\mathrm{N}_{2}$ flow regulated by a mass flow controller (MFC3).

The balance has a dynamic range of $0-100 \mathrm{mg}$. Typical dry mass of particles used in our experiments are in the range of $1-10 \mathrm{mg}$ so that the total mass of particles, due to adsorption of water at high $\mathrm{RH}$, does not exceed the upper limit of mass range. Powdered particles are transferred into the sample pan using a small stainless-steel spatula. The mass of the sample would not affect the measured mass ratio of dry particles to associated water under a given condition; however, it would take more time to reach the equilibrium if the sample mass is larger. The stated sensitivity of the balance is $<0.1 \mu \mathrm{g}$ with a weighing accuracy of $\pm 0.1 \%$, a weighing precision of $\pm 0.01 \%$, and a signal resolution of $<0.01 \mu \mathrm{g}$. The $24 \mathrm{~h}$ baseline drift is stated to be $<5 \mu \mathrm{g}$ for an empty metalized quartz pan at $25^{\circ} \mathrm{C}$ and $20 \% \mathrm{RH}$. This is equivalent to a relative mass change of $<0.05 \%$ if the sample mass is $10 \mathrm{mg}$. As shown Sect. 3.3, experimental tests do suggest that such performance can be reached.

\subsubsection{Humidity chamber}

The humidity chamber is used to regulate the temperature and RH under which hygroscopicity and/or water adsorption of particles are investigated. Inside the humidity chamber are housed a reference chamber (in which an empty pan is connected to the balance) and a sample chamber (in which a sample pan is connected to the balance). A dry $\mathrm{N}_{2}$ flow (regulated by MFC2) is delivered through a humidifier and then mixed with the second dry $\mathrm{N}_{2}$ flow (regulated by MFC1). The total flow is set to $200 \mathrm{sccm}$, and the ratio of these two flows can be adjusted in order to regulate the final RH. After mixing, the flow is then split into two flows, one delivered into the reference chamber and the other into the sample chamber. Therefore, both chambers should have the same temperature and RH. Temperature inside the humidity chamber can be adjusted from 5 to $85^{\circ} \mathrm{C}$ with a stated stability of $\pm 0.1^{\circ} \mathrm{C}$, and RH can be varied between 0 and $98 \%$. High accuracy in RH control, with a stated absolute accuracy of $\pm 1 \%$, is achieved by precisely controlling the dry and humidified $\mathrm{N}_{2}$ flow rates, using regularly calibrated mass flow controllers. The accuracy of RH control is routinely checked by measurement of the DRH of $\mathrm{NaBr}$, as detailed in Sect. 3.1. In addition, as shown in Fig. 1, two capacitance RH sensors are used to check relative humidity in the chamber.

The main advantage of using a reference chamber and a sample chamber is that the amount of water adsorbed by the empty pan and the attached wire can be simultaneously determined (and automatically subtracted using the provided software) under the same condition when water uptake by particles under investigation is being measured. In addition, the effect of buoyancy, which varies with RH (Beyer et al., 2014; Schroeder and Beyer, 2016), is also automatically taken into account by using an empty pan as the reference. Semispherical quartz crucibles with a volume of $180 \mu \mathrm{L}$, provided by the manufacturer, are used in this work as sample pans.

\subsubsection{Other features}

Q5000SA is equipped with a programmable autosampler designed to deliver sample pans into the humidity chamber. The autosampler can host up to 10 sample pans; however, in order to minimize contamination by lab air, only one sample pan is uploaded into the autosampler immediately prior to the measurement. The instrument status is displayed on a touch screen for local operation. Q5000SA can also communicate with a computer via Ethernet. Two software packages are provided by the manufacturer: (1) TA Instrument Explorer Q Series is used to control the instrument, program measurement procedures, and log experimental data; (2) TA 
Universal Analysis can be used for graphing experimental data in real time, data analysis, and exporting data. Experimental data can be sampled with frequencies up to $1 \mathrm{~Hz}$.

\subsection{Experimental procedures}

In our work two major experimental protocols are developed to (1) determine the DRH and (2) quantify water adsorption and/or mass hygroscopic growth. Corresponding experimental procedures are detailed below.

\subsubsection{DRH determination}

Based on the standard recommended by American Society for Testing and Materials International (ASTM, 2007) and TA Instruments (Waguespack and Hesse, 2007), an experimental method has been developed in this work to determine the DRH of a given sample, and it consists of the following steps. After the sample pan is properly located in the humidity chamber, temperature is set to the given value. After temperature is stabilized, $\mathrm{RH}$ is set to a value which is $\sim 5 \%$ (when change/difference in RH is mentioned in this work, it always means the absolute value) higher than the anticipated DRH and the system is equilibrated for $120 \mathrm{~min}$. For example, the DRH of $\mathrm{NaBr}$ is expected to be around (5758) \%, and RH was set to $62 \%$ from 0 to $120 \mathrm{~min}$, as shown in Fig. 2a. In the last step, RH is linearly decreased with a rate of $0.2 \% \mathrm{~min}^{-1}$ to a value which is $\sim 5 \%$ lower than the anticipated DRH. For example, as shown in Fig. 2a, RH was decreased from $62 \%$ at $120 \mathrm{~min}$ to $54 \%$ at $160 \mathrm{~min}$, and the RH decrease rate was $0.2 \% \mathrm{~min}^{-1}$.

Figure $2 \mathrm{a}$ shows changes of $\mathrm{RH}$ and sample mass (normalized to that at $0 \mathrm{~min}$ ) as a function of time in an experiment to measure the DRH of $\mathrm{NaBr}$ at $25^{\circ} \mathrm{C}$. RH was kept at $62 \%$ in the first $120 \mathrm{~min}$ during which the sample mass increased with time. After that, RH was linearly decreased to $54 \%$ with a rate of $0.2 \% \mathrm{RH} \mathrm{min}{ }^{-1}$, and during this period the sample mass first continued to increase to a maximum value and then decreased with time. The sample mass in the second period (120-160 min, as shown in Fig. 2a) is plotted as a function of $\mathrm{RH}$, and the $\mathrm{RH}(57.6 \%$ in this case) at which the sample mass reached the maximum value is equal to the measured DRH (ASTM, 2007). Measurement of a DRH usually takes $\sim 3 \mathrm{~h}$ in total, and experimental data such as $\mathrm{RH}$ and sample mass are recorded with a time resolution of $10 \mathrm{~s}$. If the DRH is unknown, we can increase the upper RH and decrease the lower RH used in the measurement so that the DRH falls into the given RH range. Increasing RH range used in the measurement will of course lead to the increase of experimental time required.

A second method has been developed to measure DRH at a given temperature. The particle sample is first dried at $0 \% \mathrm{RH}$ until its relative mass change is $<0.05 \%$ within $30 \mathrm{~min}$. RH is then increased to a value which is typically (5-10) \% lower than the expected DRH and kept at this level for $30 \mathrm{~min}$. After that, RH is stepwise increased with an increment of $1 \%$ per step, and at each step RH stays constant for $30 \mathrm{~min}$. The DRH is equal to the RH at which a significant increase in sample mass is first observed. Figure 3 shows changes in RH and normalized sample mass as a function of time in an experiment designed to measure the DRH of $\left(\mathrm{NH}_{4}\right)_{2} \mathrm{SO}_{4}$ at $25^{\circ} \mathrm{C}$. As shown in the shadowed region in Fig. 3, a sharp increase in normalized sample mass was first observed when RH was increased from 79 to $80 \%$, suggesting that deliquescence of $\left(\mathrm{NH}_{4}\right)_{2} \mathrm{SO}_{4}$ occurred between 79 and $80 \% \mathrm{RH}$ at $25^{\circ} \mathrm{C}$. Further increase in $\mathrm{RH}$ from 80 to $81 \%$ would cause sharper increase in sample mass, confirming that deliquescence indeed occurred. DRH values measured by the two methods agree with each other, and the second method is preferred because the occurrence of deliquescence can be easily visualized from the experimental data.

\subsubsection{Quantification of water adsorption and/or mass hygroscopic growth}

The following experimental procedures are used to determine the amount of water adsorbed by a material (i.e., MGFs): (1) a sample pan is delivered into the humidity chamber and temperature in the humidity chamber is set to a given value. (2) After temperature becomes stable, RH in the humidity chamber is set to $0 \%$ and the sample is equilibrated with the environment until its mass change is $<0.05 \%$ within $30 \mathrm{~min}$. (3) $\mathrm{RH}$ is increased to a given value and the sample is equilibrated with the environment again until its mass change is smaller than a certain value (typically $0.05 \%$ for less hygroscopic materials such as $\mathrm{CaCO}_{3}$ and fresh soot, and $0.1 \%$ for more hygroscopic materials such as $\left(\mathrm{NH}_{4}\right)_{2} \mathrm{SO}_{4}$ and $\left.\mathrm{NaCl}\right)$ within 30 min. (4) RH is further increased to another given value and the sample is equilibrated with the environment. The following assumptions are made to convert the mass of adsorbed water to its surface coverage (Tang et al., 2016): (1) particles are spherical, with a uniform diameter of $1 \mu \mathrm{m}$ and a density of $2.5 \mathrm{~g} \mathrm{~cm}^{-3}$; and (2) the average surface area that an adsorbed water molecule occupies is $1 \times 10^{-15} \mathrm{~cm}^{2}$. Under these assumptions, a mass change of $0.05 \%$ (relative to the dry mass) due to adsorption of water is equal to a surface coverage of 0.7 monolayers for adsorbed water.

All the processes are programmed, with the flexibility to choose the number of RH steps and the corresponding RH values. Experimental data such as $\mathrm{RH}$ and sample mass are recorded with a time resolution of $30 \mathrm{~s}$. Relevant experimental results will be presented and discussed in Sects. 3.3 and 3.4.

\subsection{Chemicals}

Sodium bromide, provided by TA Instruments as a reference material for RH calibration, was supplied by Alfa Aesar with a stated purity of $>99.7 \%$. Ammonium sulfate (purity: $>99.0 \%$ ), sodium chloride (purity: $>99.5 \%$ ), potassium 

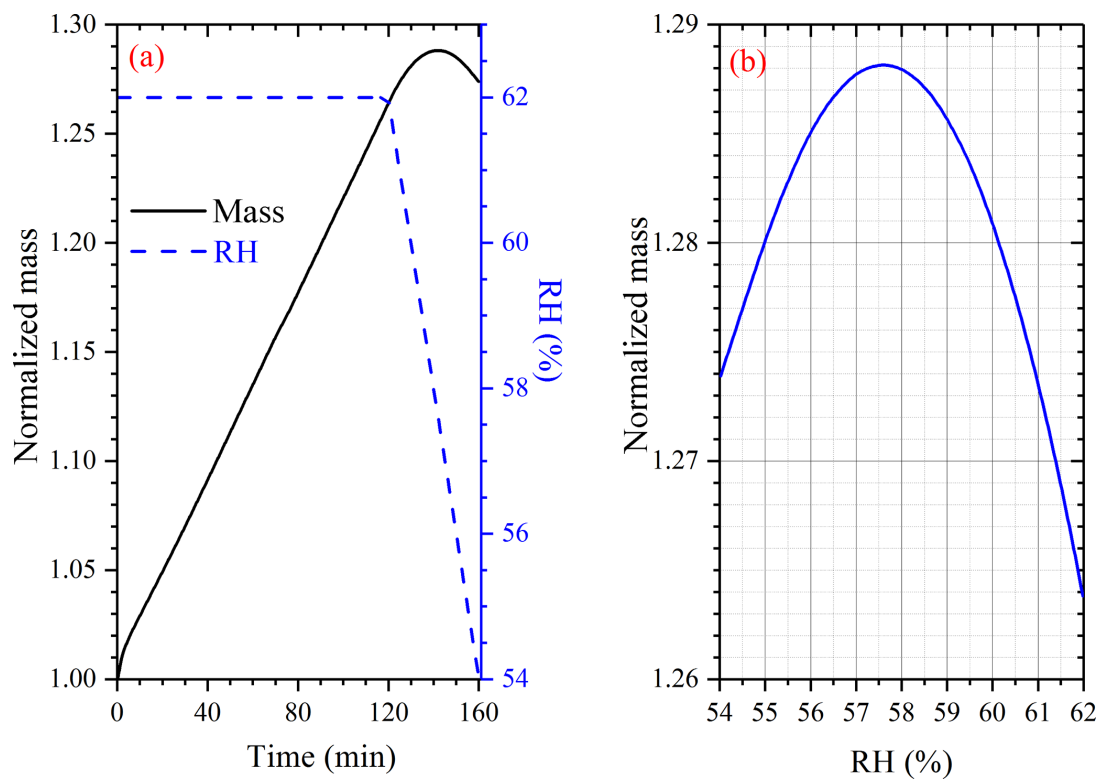

Figure 2. Typical experimental data in determination of DRH at a given temperature $\left(\mathrm{NaBr}\right.$ at $25^{\circ} \mathrm{C}$ as an example) using Q5000SA by linearly decreasing RH. (a) Change of normalized sample mass (solid curve, left $y$ axis) and RH (dashed curve, right $y$ axis) as a function of time. (b) Change of normalized sample mass as a function of RH when RH decreased linearly from 62 to $54 \%$.

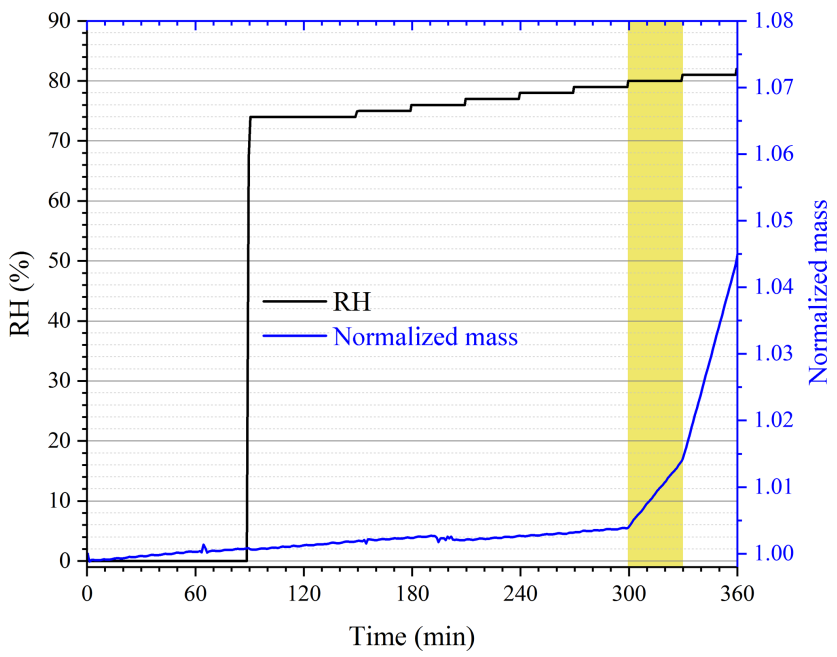

Figure 3. Typical experimental data in determination of DRH at a given temperature by stepwise increasing $\mathrm{RH}$. The experiment displayed in this figure was conducted to measure DRH of $\left(\mathrm{NH}_{4}\right)_{2} \mathrm{SO}_{4}$ at $25^{\circ} \mathrm{C}$.

chloride (purity: $>99.5 \%$ ), magnesium nitrate hexahydrate (purity: $>99.0 \%$ ), magnesium chloride hexahydrate (purity: $>99.0 \%$ ), calcium bromide (purity: $>99.98 \%$ ), and calcium sulfate dihydrate (purity: $>99 \%$ ) were purchased from Sigma-Aldrich. All the chemicals were used without further pretreatment.

\section{Results and discussion}

\subsection{RH calibration}

RH in vapor sorption analyzers and/or thermogravimetric analyzers can be calibrated/verified by determining the DRH of a reference material with a well-defined DRH (ASTM, 2007). In this work, $\mathrm{NaBr}$ provided by $\mathrm{TA}$ Instruments is used as the reference material (Waguespack and Hesse, 2007). We compare our measured DRHs of $\mathrm{NaBr}$ at six different temperatures with those reported by a previous study (Greenspan, 1977). The results are summarized in Table 1, suggesting that the differences between our measured and previous reported DRHs is $<1 \% \mathrm{RH}$ for temperatures ranging from 5 to $30^{\circ} \mathrm{C}$. The agreement is excellent, especially considering that (1) the RH has a stated accuracy of $\pm 1 \%$ for our instrument and (2) DRH values reported by Greenspan (1977) typically have errors of $\pm 0.5 \%$. Further inspection of results compiled in Table 1 reveals that the difference is larger at lower temperature and becomes smaller at higher temperature.

DRH values reported by Greenspan (1977), widely accepted as standard values, are recommended by the instrument manufacturer (Waguespack and Hesse, 2007) and also used in this study to calibrate our measure RH by taking into account the difference between our measured DRHs and those reported by Greenspan (1977) for $\mathrm{NaBr}$ at different temperatures. All the RHs reported in this work (except measured DRHs of $\mathrm{NaBr}$ listed in Table 1) have been calibrated. In our work we have not verified RH for temperature higher than $30^{\circ} \mathrm{C}$ because the atmospheric relevance is limited. It 
Table 1. Comparison of DRHs (in \%) of $\mathrm{NaBr}$ at different temperatures measured in our study with those reported in literature (Greenspan, 1977). The uncertainties for our measured DRH values are estimated to be $\pm 1 \%$.

\begin{tabular}{lrrrrrr}
\hline$T\left({ }^{\circ} \mathrm{C}\right)$ & 5 & 10 & 15 & 20 & 25 & 30 \\
\hline DRH (literature) & $63.5 \pm 0.7$ & $62.2 \pm 0.6$ & $60.7 \pm 0.5$ & $59.1 \pm 0.4$ & $57.6 \pm 0.4$ & $56.0 \pm 0.4$ \\
DRH (this work) & 62.2 & 61.2 & 60.0 & 58.5 & 57.6 & 56.1 \\
Difference in DRH & 1.3 & 1.0 & 0.7 & 0.6 & 0.0 & -0.1 \\
\hline
\end{tabular}

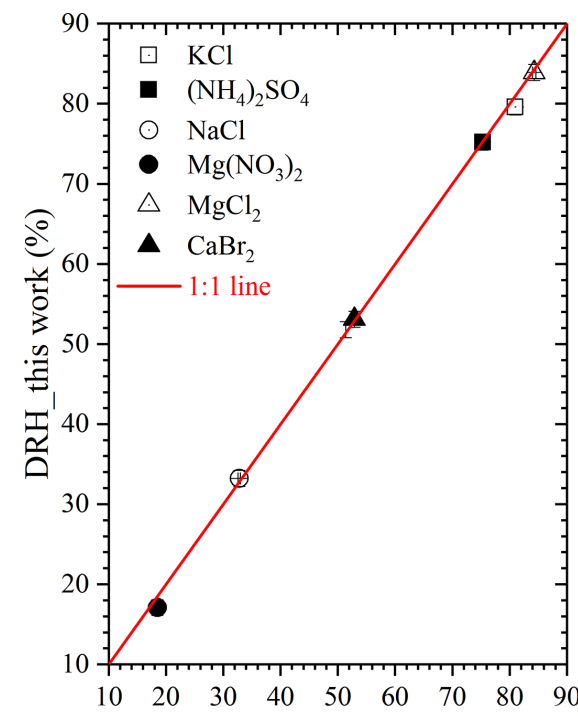

(a) DRH_reference (\%)

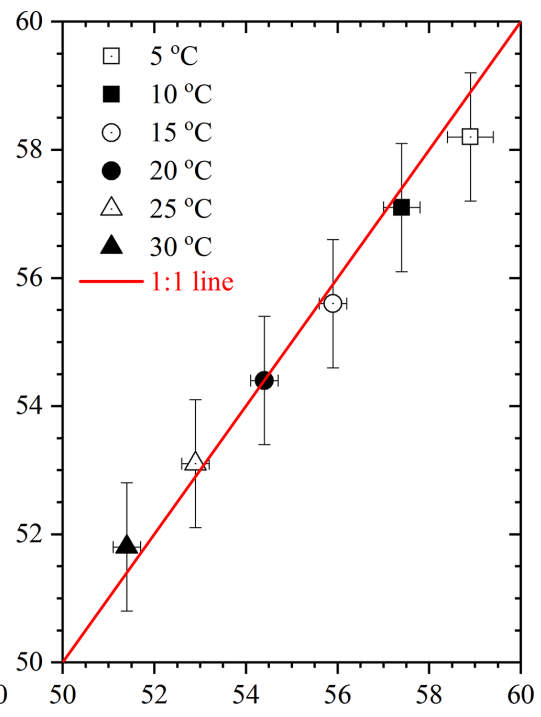

(b) DRH_reference (\%)

Figure 4. Comparison of our measured and previous reported DRHs (Greenspan, 1977). (a) DRHs of $\left(\mathrm{NH}_{4}\right)_{2} \mathrm{SO}_{4}, \mathrm{NaCl}_{2} \mathrm{MgCl}_{2} \cdot 6 \mathrm{H}_{2} \mathrm{O}$, $\mathrm{Mg}\left(\mathrm{NO}_{3}\right)_{2} \cdot 6 \mathrm{H}_{2} \mathrm{O}, \mathrm{CaBr}_{2}$, and $\mathrm{KCl}$ at $25^{\circ} \mathrm{C}$. Please note that error bars are included, but they are too small to be clearly visible. (b) DRHs of $\mathrm{Mg}\left(\mathrm{NO}_{3}\right)_{2} \cdot 6 \mathrm{H}_{2} \mathrm{O}$ as a function of temperature from 5 to $30^{\circ} \mathrm{C}$.

should be pointed out that, if necessary, RH calibration can also be carried out at higher temperature (up to $85^{\circ} \mathrm{C}$ ) using the same procedure.

\subsection{DRH measurements}

Using the experimental method detailed in Sect. 2.2.1, we have measured DRHs of $\mathrm{CaBr}_{2}, \mathrm{MgCl}_{2} \cdot 6 \mathrm{H}_{2} \mathrm{O}, \mathrm{Mg}\left(\mathrm{NO}_{3}\right)_{2}$. $6 \mathrm{H}_{2} \mathrm{O}, \mathrm{NaCl},\left(\mathrm{NH}_{4}\right)_{2} \mathrm{SO}_{4}$, and $\mathrm{KCl}$ at different temperatures from 5 to $30^{\circ} \mathrm{C}$. All the experimental results are summarized in Table 2. Figure 4a displays our measured DRHs of these compounds at $25^{\circ} \mathrm{C}$. DRHs range from $\sim 20 \%$ to almost $90 \%$ for these six compounds. As evident from Fig. 4a, our measured DRHs show excellent agreement with those reported by a previous study (Greenspan, 1977). Figure 4b shows the comparison of our measured DRHs with those reported in literature for $\mathrm{Mg}\left(\mathrm{NO}_{3}\right)_{2} \cdot 6 \mathrm{H}_{2} \mathrm{O}$ as a function of temperature $\left(5-30^{\circ} \mathrm{C}\right)$, and excellent agreement is found again. It also appears that the difference between our measured and previously reported $\mathrm{DRH}$ of $\mathrm{Mg}\left(\mathrm{NO}_{3}\right)_{2} \cdot 6 \mathrm{H}_{2} \mathrm{O}$ may show a dependence on temperature; however, the difference is not significant compared to uncertainties in DRH measurement. Careful examination of data compiled in Ta- ble 2 suggests that the absolute difference between our measured and previously reported DRHs is typically $<1 \%$.

In addition, we repeated the measurements of the DRH of $\left(\mathrm{NH}_{4}\right)_{2} \mathrm{SO}_{4}$ at $25^{\circ} \mathrm{C}$ on several different days, and in total eight measurements have been carried out. The measured DRHs range from 79.5 to $80.1 \%$. Therefore, it can be concluded from our systematical tests that the experimental method developed in our work can reliably measure DRHs from 5 to $30^{\circ} \mathrm{C}$.

\subsection{Mass hygroscopic growth measurements}

$\left(\mathrm{NH}_{4}\right)_{2} \mathrm{SO}_{4}$ and $\mathrm{NaCl}$ are important components found in tropospheric aerosol particles, and their hygroscopicity has been well understood. They have also been widely used as standard materials for validation of hygroscopicity and cloud condensation nucleation activity measurements (Good et al., 2010; Ma et al., 2010b; Tang et al., 2015). In our work we have measured MGFs of $\left(\mathrm{NH}_{4}\right)_{2} \mathrm{SO}_{4}$ and $\mathrm{NaCl}$ as a function of $\mathrm{RH}$ at two different temperatures, with the purpose to further assess the performance of our instrument. The MGF is defined as the mass ratio of particles under dry conditions to those at a given RH (Lee et al., 2008; Pope et al., 2010). 

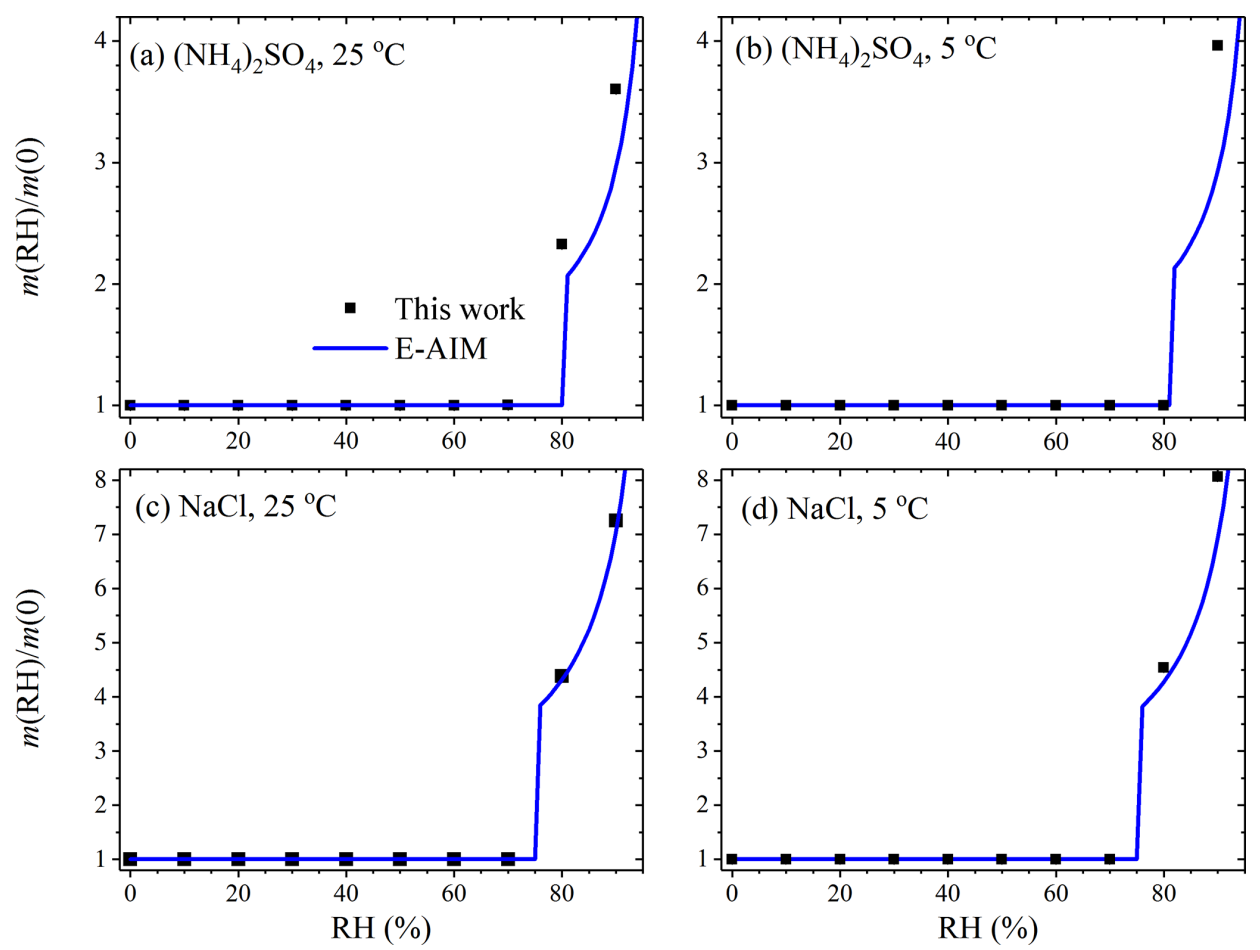

Figure 5. Comparison of mass hygroscopic growth factors measured in this work with these predicted by the $\mathrm{E}$ - $\mathrm{AIM} \mathrm{model}$. $\left(\right.$ a) $\left(\mathrm{NH}_{4}\right)_{2} \mathrm{SO}_{4}$ at $25^{\circ} \mathrm{C}$; (b) $\left(\mathrm{NH}_{4}\right)_{2} \mathrm{SO}_{4}$ at $5{ }^{\circ} \mathrm{C} ;\left(\right.$ c) $\mathrm{NaCl}$ at $25^{\circ} \mathrm{C}$; (d) $\mathrm{NaCl}$ at $5{ }^{\circ} \mathrm{C}$. Please note that error bars are included, but they are too small to be clearly visible.
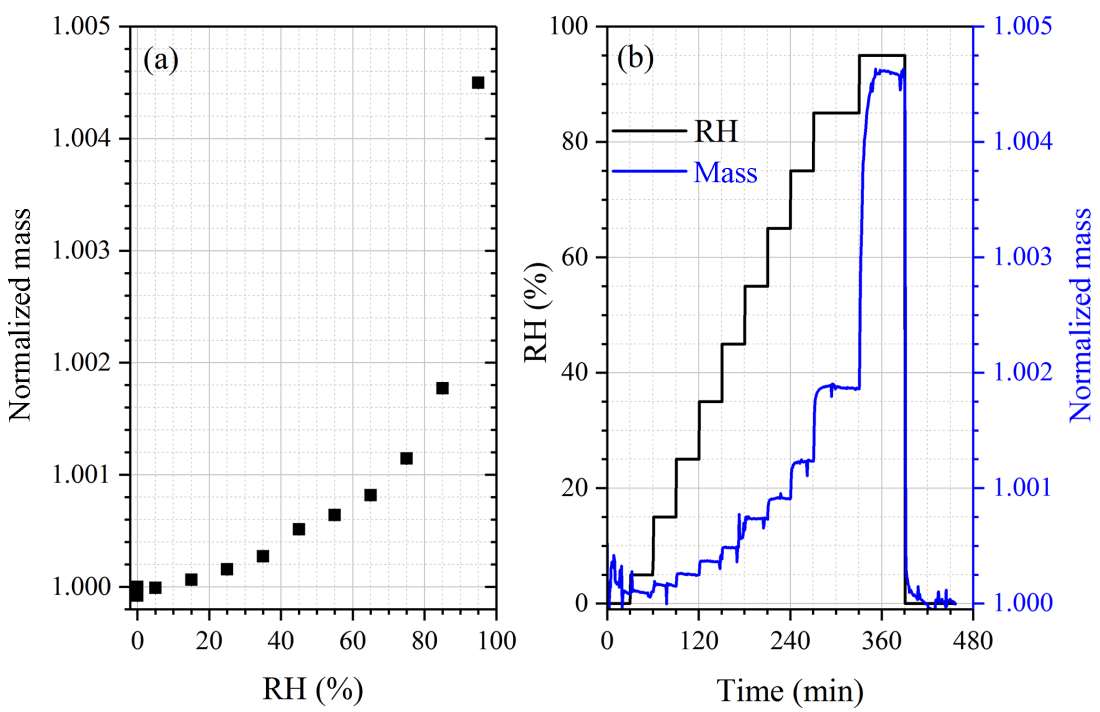

Figure 6. (a) Measured mass hygroscopic growth factors (normalized to the mass at $0 \% \mathrm{RH}$ ) of $\mathrm{CaSO}_{4} \cdot 2 \mathrm{H}_{2} \mathrm{O}$ as a function of $\mathrm{RH}$ up to $95 \%$ RH. Please note that error bars are included, but they are too small to be clearly visible. (b) Time series of RH and normalized mass of $\mathrm{CaSO}_{4} \cdot 2 \mathrm{H}_{2} \mathrm{O}$ particles with a dry mass of $\sim 9.05 \mathrm{mg}$ during a hygroscopic growth experiment. This experiment was carried out at $25^{\circ} \mathrm{C}$.

Figure 5 show the comparison of MGFs measured by our work with those predicted by the E-AIM model (Wexler and Clegg, 2002). The agreement between measured and calculated growth factors is excellent for $\mathrm{NaCl}$ at both temperatures; for $\left(\mathrm{NH}_{4}\right)_{2} \mathrm{SO}_{4}$, the agreement is not as good as $\mathrm{NaCl}$.
This may be caused by two reasons. First, after $\left(\mathrm{NH}_{4}\right)_{2} \mathrm{SO}_{4}$ is deliquesced, MGFs increase sharply with $\mathrm{RH}$, and therefore a small difference in RH would lead a relatively large change in measured MGFs; if taking into account the uncertainty in $\mathrm{RH}( \pm 1 \%)$, the difference between our measured 
Table 2. Comparison of DRHs measured by our study with those reported in literature $\left(\mathrm{Greenspan}^{1977)} \mathrm{for}_{\mathrm{CaBr}}, \mathrm{MgCl}_{2} \cdot 6 \mathrm{H}_{2} \mathrm{O}\right.$, $\mathrm{Mg}\left(\mathrm{NO}_{3}\right)_{2} \cdot 6 \mathrm{H}_{2} \mathrm{O}, \mathrm{NaCl},\left(\mathrm{NH}_{4}\right)_{2} \mathrm{SO}_{4}$ and $\mathrm{KCl}$ from 5 to $30^{\circ} \mathrm{C}$. NA: data are not available. The uncertainties for our measured DRH values are estimated to be $\pm 1 \%$.

\begin{tabular}{|c|c|c|c|c|c|c|}
\hline $\begin{array}{l}T \\
\left({ }^{\circ} \mathrm{C}\right)\end{array}$ & Literature & $\begin{array}{l}\text { This } \\
\text { work }\end{array}$ & Literature & $\begin{array}{l}\text { This } \\
\text { work }\end{array}$ & Literature & $\begin{array}{l}\text { This } \\
\text { work }\end{array}$ \\
\hline & \multicolumn{2}{|c|}{$\mathrm{CaBr}_{2}$} & \multicolumn{2}{|c|}{$\mathrm{MgCl}_{2} \cdot 6 \mathrm{H}_{2} \mathrm{O}$} & \multicolumn{2}{|c|}{$\mathrm{Mg}\left(\mathrm{NO}_{3}\right)_{2} \cdot 6 \mathrm{H}_{2} \mathrm{O}$} \\
\hline 5 & NA & 22.9 & $33.6 \pm 0.3$ & 33.3 & $58.9 \pm 0.5$ & 58.2 \\
\hline 10 & $21.6 \pm 0.5$ & 21.6 & $33.5 \pm 0.3$ & 33.9 & $57.4 \pm 0.4$ & 57.1 \\
\hline 15 & $20.2 \pm 0.5$ & 20.0 & $33.3 \pm 0.3$ & 33.6 & $55.9 \pm 0.3$ & 55.6 \\
\hline 20 & $18.5 \pm 0.5$ & 18.0 & $33.1 \pm 0.2$ & 33.5 & $54.4 \pm 0.3$ & 54.4 \\
\hline 25 & $18.5 \pm 0.5$ & 17.1 & $32.8 \pm 0.2$ & 33.2 & $52.9 \pm 0.3$ & 53.1 \\
\hline \multirow[t]{2}{*}{30} & NA & 17.7 & $32.4 \pm 0.2$ & 33.6 & $51.4 \pm 0.3$ & 51.8 \\
\hline & \multicolumn{2}{|c|}{$\mathrm{NaCl}$} & \multicolumn{2}{|c|}{$\left(\mathrm{NH}_{4}\right)_{2} \mathrm{SO}_{4}$} & \multicolumn{2}{|c|}{$\mathrm{KCl}$} \\
\hline 5 & $75.6 \pm 0.5$ & 76.0 & $82.4 \pm 0.7$ & 80.8 & $87.7 \pm 0.5$ & 86.7 \\
\hline 10 & $75.7 \pm 0.4$ & 75.7 & $82.1 \pm 0.5$ & 80.8 & $86.8 \pm 0.4$ & 86.3 \\
\hline 15 & $75.6 \pm 0.3$ & 75.7 & $81.7 \pm 0.4$ & 80.4 & $85.9 \pm 0.4$ & 85.6 \\
\hline 20 & $75.5 \pm 0.3$ & 75.6 & $81.3 \pm 0.3$ & 80.3 & $85.1 \pm 0.3$ & 85.0 \\
\hline 25 & $75.3 \pm 0.3$ & 75.2 & $81.0 \pm 0.3$ & 79.6 & $84.3 \pm 0.3$ & 83.9 \\
\hline 30 & $75.1 \pm 0.3$ & 75.5 & $80.6 \pm 0.3$ & 79.7 & $83.6 \pm 0.3$ & 83.4 \\
\hline
\end{tabular}

and predicted mass hygroscopic growth factors is $<15 \%$. Second, inspection of the data in Table 2 reveals that the difference between our measured and previously reported DRH is $<1 \%$ for all the other compounds except $\left(\mathrm{NH}_{4}\right)_{2} \mathrm{SO}_{4}$. This may indicate that the purity of $\left(\mathrm{NH}_{4}\right)_{2} \mathrm{SO}_{4}$ could lead to the small but yet detectable difference. In the near future we will purchase $\left(\mathrm{NH}_{4}\right)_{2} \mathrm{SO}_{4}$ with higher purity and measure its DRH and hygroscopic growth factors. Overall, it can be concluded from the comparison that our measured MGFs agree well with theoretical values for $\left(\mathrm{NH}_{4}\right)_{2} \mathrm{SO}_{4}$ and $\mathrm{NaCl}$ at both 5 and $25^{\circ} \mathrm{C}$. This gives us further confidence that the method developed in this work is reliable for hygroscopicity measurements of atmospheric particles.

We have also measured the MGFs of $\mathrm{CaSO}_{4} \cdot 2 \mathrm{H}_{2} \mathrm{O}$ as a function of $\mathrm{RH}$ (up to $95 \%$ ) at $25^{\circ} \mathrm{C}$. The results are plotted in Fig. 6a, and the numerical data are summarized in the appendix (Table A1). As shown in Fig. 6, the ability of $\mathrm{CaSO}_{4} \cdot 2 \mathrm{H}_{2} \mathrm{O}$ to uptake water is very limited, with the mass ratio of adsorbed water to dry particles determined to be $(0.450 \pm 0.004) \%(1 \sigma)$ at $95 \% \mathrm{RH}$. This is qualitatively consistent with two previous studies which suggested that the cloud condensation nucleation activity of calcium sulfate aerosol particles is very low (Sullivan et al., 2009a; Tang et al., 2015). More detailed comparison and discussion are beyond the scope of this paper and will be addressed in a following publication. This also implies that airborne $\mathrm{CaSO}_{4} \cdot 2 \mathrm{H}_{2} \mathrm{O}$ particles are not deliquesced for $\mathrm{RH}$ up to $95 \%$ and therefore may exist as nonspherical particles.

Figure $6 \mathrm{~b}$ displays change of $\mathrm{RH}$ and normalized sample mass with time during the measurement, suggesting that within $6 \mathrm{~h}$ our method can measure a relative mass change of $<0.025 \%$. The accuracy of mass measurement is mainly limited by long-term baseline drifts. In another experiment, a $\mathrm{CaCO}_{3}$ sample (with a dry mass of $\sim 10 \mathrm{mg}$ ) was used, and its mass was continuously monitored under dry conditions at $25^{\circ} \mathrm{C}$. Under this experimental condition, the baseline drift was determined to be $<0.05 \%$ within $24 \mathrm{~h}$.

\section{Conclusion and outlook}

The ability to uptake water vapor under subsaturated conditions is one of the most important physicochemical properties of atmospheric particles, largely determining their impacts on atmospheric chemistry and climate. In this work, we have developed a new experimental method to investigate interactions of particles with water vapor under subsaturated conditions at different temperatures from 5 to $30^{\circ} \mathrm{C}$, using a commercial vapor sorption analyzer. Operation temperature can be increased up to $85^{\circ} \mathrm{C}$, though the atmospheric relevance is limited. We have provided a detailed description of instrument configuration as well as experimental procedures to determine DRHs and MGFs. For the temperature range we have covered in this work $\left(5-30^{\circ} \mathrm{C}\right)$, our measured DRHs of six different compounds with DRHs ranging from $\sim 20$ to $\sim 90 \%$ show excellent agreement with those reported in literature. In addition, MGFs measured in our work at different $\mathrm{RH}$ values agree well with those predicted by the E-AIM model for $\left(\mathrm{NH}_{4}\right)_{2} \mathrm{SO}_{4}$ and $\mathrm{NaCl}$ at 5 and $25^{\circ} \mathrm{C}$. Therefore, we have demonstrated that experimental methods developed in our work can reliably measure DRHs and MGFs from 5 to $30^{\circ} \mathrm{C}$. 
To test the ability of this instrument to measure hygroscopic growth of compounds with low hygroscopicity, we have determined MGFs of $\mathrm{CaSO}_{4} \cdot 2 \mathrm{H}_{2} \mathrm{O}$ at $25^{\circ} \mathrm{C}$. It has been found that the ability of $\mathrm{CaSO}_{4} \cdot 2 \mathrm{H}_{2} \mathrm{O}$ to uptake water is very limited. The mass of water adsorbed by $\mathrm{CaSO}_{4} \cdot 2 \mathrm{H}_{2} \mathrm{O}$ at $95 \% \mathrm{RH}$ is only $(0.450 \pm 0.004) \%$ of its dry mass. It has also been observed that this instrument can measure a mass change of $<0.025 \%$ within $6 \mathrm{~h}$ and $<0.05 \%$ within $24 \mathrm{~h}$, and accuracy of mass change determination is mainly limited by baseline drifts. With such an accuracy, this instrument is particularly useful for quantitative determination of water adsorption and/or hygroscopicity of nonspherical particles such as mineral dust and soot.

Atmospheric aging processes are known to alter water adsorption, hygroscopicity, and cloud condensation nucleation activity of mineral dust and soot particles (Kelly and Wexler, 2005; Laskin et al., 2005; Zhang et al., 2008; Sullivan et al., 2009b; Han et al., 2013; Denjean et al., 2015; Tang et al., 2016). In the future, this instrument will be used to investigate water adsorption and hygroscopicity of mineral dust and soot particles before and after chemical processing. We note that this technique also has a few drawbacks: (1) this technique cannot be used to examine supersaturated droplets or determine efflorescence relative humidities due to the contact of particles with the sample pan; (2) substantial amount of particles, typically around or larger than $1 \mathrm{mg}$, are required by this technique, limiting its application to atmospheric particles even after they are collected (e.g., using a filter or an impactor plate); and (3) the experiment is very time consuming, and a typical experiment can take several hours and even a few days, depending on experimental conditions.
Data availability. Experimental data presented in this work are available upon request (Mingjin Tang: mingjintang@gig.ac.cn).

Competing interests. The authors declare that they have no conflict of interest.

Acknowledgement. Financial support provided by Chinese National Science Foundation (grant nos. 91644106 and 41675120), Chinese Academy of Sciences international collaborative project (grant no. 132744KYSB20160036) and State Key Laboratory of Organic Geochemistry (grant no. SKLOGA201603A) is acknowledged. Mingjin Tang would like to thank the CAS Pioneer Hundred Talents program for providing a starting grant and Yongjie $\mathrm{Li}$ would like to acknowledge funding support of the start-up research grant from University of Macau (SRG2015-00052-FST). This is contribution no. IS-2438 from GIGCAS.

Edited by: Hartwig Harder

Reviewed by: four anonymous referees 
Appendix A

Table A1. Normalized mass of $\mathrm{CaSO}_{4} \cdot 2 \mathrm{H}_{2} \mathrm{O}$ as a function of $\mathrm{RH}$ at $25^{\circ} \mathrm{C}$.

\begin{tabular}{lrrrrrr}
\hline RH $(\%)$ & 0 & 5 & 15 & 25 & 35 & 45 \\
\hline Normalized mass & 1.00000 & 0.99999 & 1.00006 & 1.00016 & 1.00027 & 1.00051 \\
Error & 0.00001 & 0.00002 & 0.00001 & 0.00001 & 0.00004 & 0.00005 \\
\hline RH $(\%)$ & 55 & 65 & 75 & 85 & 95 & 0 \\
\hline Normalized mass & 1.00064 & 1.00082 & 1.00114 & 1.00177 & 1.00450 & 0.99992 \\
error & 0.00002 & 0.00001 & 0.00001 & 0.00001 & 0.00004 & 0.00001 \\
\hline
\end{tabular}




\section{References}

Ardon-Dryer, K., Garimella, S., Huang, Y. W., Christopoulos, C., and Cziczo, D. J.: Evaluation of DMA size selection of dry dispersed mineral dust particles, Aerosol Sci. Tech., 49, 828-841, 2015.

Arenas, K. J. L., Schill, S. R., Malla, A., and Hudson, P. K.: Deliquescence phase transition measurements by quartz crystal microbalance frequency shifts, J. Phys. Chem. A, 116, 7658-7667, 2012 .

ASTM: Standard Test Method for Humidity Calibration (or Conformation) of Humidity Generators for Use with Thermogravimetric Analyzers, American Society for Testing and Materials International, West Conshohocken, PA 19428, USA, https://doi.org/10.1520/E2551-07, 2007.

Attwood, A. R. and Greenslade, M. E.: Optical properties and associated hygroscopicity of clay aerosols, Aerosol Sci. Tech., 45, 1350-1359, 2011.

Beyer, K. D., Schroeder, J. R., and Kissinger, J. A.: Temperaturedependent deliquescence relative humidities and water activities using humidity controlled thermogravimetric analysis with application to malonic acid, J. Phys. Chem. A, 118, 2488-2497, 2014.

Chan, M. N., Kreidenweis, S. M., and Chan, C. K.: Measurements of the hygroscopic and deliquescence properties of organic compounds of different solubilities in water and their relationship with cloud condensation nuclei activities, Environ. Sci. Technol., 42, 3602-3608, 2008.

Clegg, S. L., Brimblecombe, P., and Wexler, A. S.: Thermodynamic model of the system $\mathrm{H}^{+}-\mathrm{NH}_{4}^{+}-\mathrm{Na}^{+}-\mathrm{SO}_{4}^{2-}-\mathrm{NO}_{3}^{-}-\mathrm{Cl}^{-}-\mathrm{H}_{2} \mathrm{O}$ at 298.15 K, J. Phys. Chem. A, 102, 2155-2171, 1998.

Denjean, C., Caquineau, S., Desboeufs, K., Laurent, B., Maille, M., Quiñones Rosado, M., Vallejo, P., Mayol-Bracero, O. L., and Formenti, P.: Long-range transport across the Atlantic in summertime does not enhance the hygroscopicity of African mineral dust, Geophys. Res. Lett., 42, 7835-7843, 2015.

Estillore, A. D., Hettiyadura, A. P. S., Qin, Z., Leckrone, E., Wombacher, B., Humphry, T., Stone, E. A., and Grassian, V. H.: Water uptake and hygroscopic growth of organosulfate aerosol, Environ. Sci. Technol., 50, 4259-4268, 2016.

Farmer, D. K., Cappa, C. D., and Kreidenweis, S. M.: Atmospheric processes and their controlling influence on cloud condensation nuclei activity, Chem. Rev., 115, 4199-4217, 2015.

Freedman, M. A., Hasenkopf, C. A., Beaver, M. R., and Tolbert, M. A.: Optical properties of internally mixed aerosol particles composed of dicarboxylic acids and ammonium sulfate, J. Phys. Chem. A, 113, 13584-13592, 2009.

Friese, E. and Ebel, A.: Temperature dependent thermodynamic model of the system $\mathrm{H}^{+}-\mathrm{NH}_{4}^{+}-\mathrm{Na}^{+}-\mathrm{SO}_{4}^{2-}-\mathrm{NO}_{3}^{-}-\mathrm{Cl}^{-}-\mathrm{H}_{2} \mathrm{O}$, J. Phys. Chem. A, 114, 11595-11631, 2010.

Frinak, E. K., Mashburn, C. D., Tolbert, M. A., and Toon, O. B.: Infrared characterization of water uptake by low-temperature Na-montmorillonite: implications for Earth and Mars, J. Geophys. Res.-Atmos., 110, D09308, https://doi.org/10.1029/2004JD005647, 2005.

Good, N., Coe, H., and McFiggans, G.: Instrumentational operation and analytical methodology for the reconciliation of aerosol water uptake under sub- and supersaturated conditions, Atmos. Meas. Tech., 3, 1241-1254, https://doi.org/10.5194/amt-3-1241$2010,2010$.
Goodman, A. L., Bernard, E. T., and Grassian, V. H.: Spectroscopic study of nitric acid and water adsorption on oxide particles: enhanced nitric acid uptake kinetics in the presence of adsorbed water, J. Phys. Chem. A, 105, 6443-6457, 2001.

Greenspan, L.: Humidity fixed points of binary saturated aqueous solutions, J. Res. NBS A Phys. Ch., 81, 89-96, 1977.

Griffiths, P. T., Borlace, J. S., Gallimore, P. J., Kalberer, M., Herzog, M., and Pope, F. D.: Hygroscopic growth and cloud activation of pollen: a laboratory and modelling study, Atmos. Sci. Lett., 13, 289-295, 2012.

Gustafsson, R. J., Orlov, A., Badger, C. L., Griffiths, P. T., Cox, R. A., and Lambert, R. M.: A comprehensive evaluation of water uptake on atmospherically relevant mineral surfaces: DRIFT spectroscopy, thermogravimetric analysis and aerosol growth measurements, Atmos. Chem. Phys., 5, 3415-3421, https://doi.org/10.5194/acp-5-3415-2005, 2005.

Han, C., Liu, Y. C., and He, H.: Heterogeneous photochemical aging of soot by $\mathrm{NO}_{2}$ under simulated sunlight, Atmos. Environ., 64, 270-276, 2013.

Herich, H., Tritscher, T., Wiacek, A., Gysel, M., Weingartner, E., Lohmann, U., Baltensperger, U., and Cziczo, D. J.: Water uptake of clay and desert dust aerosol particles at sub- and supersaturated water vapor conditions, Phys. Chem. Chem. Phys., 11, 7804-7809, 2009.

Kelly, J. T. and Wexler, A. S.: Thermodynamics of carbonates and hydrates related to heterogeneous reactions involving mineral aerosol, J. Geophys. Res.-Atmos, 110, D11201, https://doi.org/10.1029/2004jd005583, 2005.

Koehler, K. A., Kreidenweis, S. M., DeMott, P. J., Petters, M. D., Prenni, A. J., and Carrico, C. M.: Hygroscopicity and cloud droplet activation of mineral dust aerosol, Geophys. Res. Lett., 36, L08805, https://doi.org/10.1029/2009g1037348, 2009.

Krieger, U. K., Marcolli, C., and Reid, J. P.: Exploring the complexity of aerosol particle properties and processes using single particle techniques, Chem. Soc. Rev., 41, 6631-6662, 2012.

Laskin, A., Iedema, M. J., Ichkovich, A., Graber, E. R., Taraniuk, I., and Rudich, Y.: Direct observation of completely processed calcium carbonate dust particles, Faraday Discuss., 130, 453-468, 2005.

Lee, A. K. Y., Ling, T. Y., and Chan, C. K.: Understanding hygroscopic growth and phase transformation of aerosols using single particle Raman spectroscopy in an electrodynamic balance, Faraday Discuss., 137, 245-263, 2008.

Lei, T., Zuend, A., Wang, W. G., Zhang, Y. H., and Ge, M. F.: Hygroscopicity of organic compounds from biomass burning and their influence on the water uptake of mixed organic ammonium sulfate aerosols, Atmos. Chem. Phys., 14, 11165-11183, https://doi.org/10.5194/acp-14-11165-2014, 2014.

Liu, P. F., Li, Y. J., Wang, Y., Gilles, M. K., Zaveri, R. A., Bertram, A. K., and Martin, S. T.: Lability of secondary organic particulate matter, P. Natl. Acad. Sci. USA, 113, 12643-12648, 2016.

Ma, Q. X., He, H., and Liu, Y. C.: In situ DRIFTS study of hygroscopic behavior of mineral aerosol, J. Environ. Sci., 22, 555-560, 2010a.

Ma, Q. X., Liu, Y. C., and He, H.: The utilization of physisorption analyzer for studying the hygroscopic properties of atmospheric relevant particles, J. Phys. Chem. A, 114, 4232-4237, 2010 b. 
Ma, Q. X., Liu, Y. C., Liu, C., and He, H.: Heterogeneous reaction of acetic acid on $\mathrm{MgO}, \alpha-\mathrm{Al}_{2} \mathrm{O}_{3}$, and $\mathrm{CaCO}_{3}$ and the effect on the hygroscopic behavior of these particles, Phys. Chem. Chem. Phys., 14, 8403-8409, 2012.

Martin, S. T.: Phase transitions of aqueous atmospheric particles, Chem. Rev., 100, 3403-3453, 2000.

McFiggans, G., Artaxo, P., Baltensperger, U., Coe, H., Facchini, M. C., Feingold, G., Fuzzi, S., Gysel, M., Laaksonen, A., Lohmann, U., Mentel, T. F., Murphy, D. M., O'Dowd, C. D., Snider, J. R., and Weingartner, E.: The effect of physical and chemical aerosol properties on warm cloud droplet activation, Atmos. Chem. Phys., 6, 2593-2649, https://doi.org/10.5194/acp-6-25932006, 2006.

Petters, M. D. and Kreidenweis, S. M.: A single parameter representation of hygroscopic growth and cloud condensation nucleus activity, Atmos. Chem. Phys., 7, 1961-1971, https://doi.org/10.5194/acp-7-1961-2007, 2007.

Pöschl, U.: Atmospheric aerosols: composition, transformation, climate and health effects, Angew. Chem. Int. Edit., 44, 7520-7540, 2005.

Pope, F. D.: Pollen grains are efficient cloud condensation nuclei, Environ. Res. Lett., 5, 044015, https://doi.org/10.1088/17489326/5/4/044015, 2010.

Pope, F. D., Dennis-Smither, B. J., Griffiths, P. T., Clegg, S. L., and Cox, R. A.: Studies of single aerosol particles containing malonic acid, glutaric acid, and their mixtures with sodium chloride. I. Hygroscopic growth, J. Phys. Chem. A, 114, 5335-5341, 2010.

Pruppacher, H. R. and Klett, J. D.: Microphysics of Clouds and Precipitation, Kluwer Academic Publishers, Dordrecht, Netherlands 1994.

Robinson, C. B., Schill, G. P., Zarzana, K. J., and Tolbert, M. A.: Impact of organic coating on optical growth of ammonium sulfate particles, Environ. Sci. Technol., 47, 13339-13346, 2013.

Rubasinghege, G. and Grassian, V. H.: Role(s) of adsorbed water in the surface chemistry of environmental interfaces, Chem. Commun., 49, 3071-3094, 2013.

Schroeder, J. R. and Beyer, K. D.: Deliquescence relative humidities of organic and inorganic salts important in the atmosphere, J. Phys. Chem. A, 120, 9948-9957, 2016.

Schuttlefield, J., Al-Hosney, H., Zachariah, A., and Grassian, V. H.: Attenuated total reflection fourier transform infrared spectroscopy to investigate water uptake and phase transitions in atmospherically relevant particles, Appl. Spectrosc., 61, 283-292, 2007 a.

Schuttlefield, J. D., Cox, D., and Grassian, V. H.: An investigation of water uptake on clays minerals using ATRFTIR spectroscopy coupled with quartz crystal microbalance measurements, J. Geophys. Res.-Atmos., 112, D21303, https://doi.org/10.1029/2007JD008973, 2007b.

Seinfeld, J. H. and Pandis, S. N.: Atmospheric Chemistry Physics: from Air Pollution to Climate Change, Wiley Interscience, New York, 2006.

Sullivan, R. C., Moore, M. J. K., Petters, M. D., Kreidenweis, S. M., Roberts, G. C., and Prather, K. A.: Effect of chemical mixing state on the hygroscopicity and cloud nucleation properties of calcium mineral dust particles, Atmos. Chem. Phys., 9, 33033316, https://doi.org/10.5194/acp-9-3303-2009, 2009a.
Sullivan, R. C., Moore, M. J. K., Petters, M. D., Kreidenweis, S. M., Roberts, G. C., and Prather, K. A.: Timescale for hygroscopic conversion of calcite mineral particles through heterogeneous reaction with nitric acid, Phys. Chem. Chem. Phys., 11, 78267837, 2009b.

Swietlicki, E., Hansson, H. C., Hameri, K., Svenningsson, B., Massling, A., McFiggans, G., McMurry, P. H., Petaja, T., Tunved, P., Gysel, M., Topping, D., Weingartner, E., Baltensperger, U., Rissler, J., Wiedensohler, A., and Kulmala, M.: Hygroscopic properties of submicrometer atmospheric aerosol particles measured with H-TDMA instruments in various environments - a review, Tellus B, 60, 432-469, 2008.

Tang, M. J., Whitehead, J., Davidson, N. M., Pope, F. D., Alfarra, M. R., McFiggans, G., and Kalberer, M.: Cloud condensation nucleation activities of calcium carbonate and its atmospheric ageing products, Phys. Chem. Chem. Phys., 17, 32194 32203, 2015.

Tang, M. J., Cziczo, D. J., and Grassian, V. H.: Interactions of water with mineral dust aerosol: water adsorption, hygroscopicity, cloud condensation and ice nucleation, Chem. Rev., 116, 42054259, 2016.

Vali, G., DeMott, P. J., Möhler, O., and Whale, T. F.: Technical Note: A proposal for ice nucleation terminology, Atmos. Chem. Phys., 15, 10263-10270, https://doi.org/10.5194/acp-15-102632015, 2015.

Veghte, D. P. and Freedman, M. A.: The necessity of microscopy to characterize the optical properties of size-selected, nonspherical aerosol particles, Anal. Chem., 84, 9101-9108, 2012.

Vlasenko, A., Sjogren, S., Weingartner, E., Gaggeler, H. W., and Ammann, M.: Generation of submicron Arizona test dust aerosol: chemical and hygroscopic properties, Aerosol Sci. Tech., 39, 452-460, 2005.

Waguespack, L. and Hesse, N.: TN66: Humidity Calibration of Dynamic Vapor Sorption (DVS) Instruments, TA Instruments, New Castle, DE 19720, USA, 2007.

Wexler, A. S. and Clegg, S. L.: Atmospheric aerosol models for systems including the ions $\mathrm{H}^{+}, \mathrm{NH}_{4}^{+}, \mathrm{Na}^{+}, \mathrm{SO}_{4}^{2-}$, $\mathrm{NO}_{3}^{-}, \mathrm{Cl}^{-}, \mathrm{Br}^{-}$, and $\mathrm{H}_{2} \mathrm{O}$, J. Geophys. Res.-Atmos, 107, 4207, https://doi.org/10.1029/2001JD000451, 2002.

Wu, Z. J., Nowak, A., Poulain, L., Herrmann, H., and Wiedensohler, A.: Hygroscopic behavior of atmospherically relevant water-soluble carboxylic salts and their influence on the water uptake of ammonium sulfate, Atmos. Chem. Phys., 11, 1261712626, https://doi.org/10.5194/acp-11-12617-2011, 2011.

Yeşilbaş, M. and Boily, J.-F.: Particle size controls on water adsorption and condensation regimes at mineral surfaces, Sci. Rep.-UK, 6, 32136, https://doi.org/10.1038/srep32136, 2016.

Zhang, R. Y., Khalizov, A. F., Pagels, J., Zhang, D., Xue, H. X., and McMurry, P. H.: Variability in morphology, hygroscopicity, and optical properties of soot aerosols during atmospheric processing, P. Natl. Acad. Sci. USA, 105, 10291-10296, 2008. 